\title{
Regulation of Radial Glial Motility by Visual Experience
}

\author{
Marc Tremblay, ${ }^{1,2,3}$ Vincent Fugère, ${ }^{4}$ Jennifer Tsui, ${ }^{2,3}$ Anne Schohl, ${ }^{3}$ Aydin Tavakoli, ${ }^{1,2,3}$ Bruno A. N. Travençolo, ${ }^{5}$ \\ Luciano da F. Costa, ${ }^{5}$ and Edward S. Ruthazer ${ }^{1,2,3,4}$ \\ ${ }^{1}$ McGill Graduate Program in Neuroscience, ${ }^{2}$ McGill Program in NeuroEngineering, ${ }^{3}$ Department of Neurology and Neurosurgery, and ${ }^{4}$ Department of \\ Psychology, Montreal Neurological Institute, McGill University, Montreal, Quebec H3A 2B4, Canada, and 5Instituto de Física de São Carlos, Universidade de \\ São Paulo, São Carlos, São Paulo, 13560-970, Brazil
}

Radial glia in the developing optic tectum express the key guidance molecules responsible for topographic targeting of retinal axons. However, the extent to which the radial glia are themselves influenced by retinal inputs and visual experience remains unknown. Using multiphoton live imaging of radial glia in the optic tectum of intact Xenopus laevis tadpoles in conjunction with manipulations of neural activity and sensory stimuli, radial glia were observed to exhibit spontaneous calcium transients that were modulated by visual stimulation. Structurally, radial glia extended and retracted many filopodial processes within the tectal neuropil over minutes. These processes interacted with retinotectal synapses and their motility was modulated by nitric oxide (NO) signaling downstream of neuronal NMDA receptor (NMDAR) activation and visual stimulation. These findings provide the first in vivo demonstration that radial glia actively respond both structurally and functionally to neural activity, via NMDAR-dependent NO release during the period of retinal axon ingrowth.

\section{Introduction}

Glial processes in the brain have been shown to physically ensheath synaptic terminals in the hippocampus and cerebellum, where they actively participate in synapse formation, spine maturation, and synaptic plasticity (Murai et al., 2003; Christopherson et al., 2005; Panatier et al., 2006a; Stellwagen and Malenka, 2006; Todd et al., 2006; Jourdain et al., 2007; Nestor et al., 2007; Nishida and Okabe, 2007). In addition to interactions with synapses, rapid dynamic remodeling of astrocytes has been demonstrated in hippocampal cultures and in acute hindbrain slices (Hirrlinger et al., 2004; Haber et al., 2006). Bergmann glia in the cerebellum exhibit a similar form of dynamic behavior (Lippman et al., 2008). Early in development the high degree of motility of Bergmann glial processes appears to be permissive for synapse formation, whereas later in life glial structural remodeling helps modulate synaptic efficacy through transmitter uptake and delivery of gliotransmitters.

These facts underscore the significance of interactions between glia and neurons in the development and the function of the CNS and paint a picture of glia as structurally dynamic and responsive to the environment. However, because existing data on the morphological motility of macroglia comes either from histological analysis or from imaging of acute slices and cultures,

\footnotetext{
Received July 20, 2009; revised Sept. 14, 2009; accepted 0ct. 5, 2009.

This work was supported by funding from the Canadian Institutes of Health Research (E.S.R.), the EJLB Foundation (E.S.R.), the National Alliance for Research on Schizophrenia and Depression (E.S.R.), the March of Dimes (E.S.R.), the Natural Sciences and Engineering Research Council of Canada-Undergraduate Student Research Awards Program (V.F.), Fonds de la recherche en santé Québec (J.T.), Fundação de Amparo à Pesquisa do Estado de São Paulo (FAPESP) 07/02938-5 (B.A.N.T.), Conselho Nacional de Desenvolvimento Científico e Tecnológico (CNPq) 301303/ 06-1 (L.d.F.C.), and FAPESP 05/00587-5 (L.d.F.C..). We thank Drs. Rebecca Ewald and Hollis Cline for providing the Xenopus NR1 CDNA, Dr. Keith Murai for the EGFP-F construct, and Dr. Roger Tsien for the mCherry plasmid.

Correspondence should be addressed to Edward S. Ruthazer, Montreal Neurological Institute, McGill University, 3801 University Street, Montreal, QC H3A 2B4, Canada. E-mail: edward.ruthazer@mcgill.ca.

D0I:10.1523/JNEUROSCI.3542-09.2009

Copyright $\odot 2009$ Society for Neuroscience ～0270-6474/09/2914066-11\$15.00/0
}

rather than imaging in the intact brain, the normal kinetics of glial motility in response to natural sensory experience has not been described. We have therefore performed multiphoton timelapse imaging of glial cells in the visual system of intact, albino Xenopus laevis tadpoles with the goal of describing the dynamic behaviors of tectal radial glia in response to sensory stimulation and synaptic activity in vivo.

The predominant form of macroglia in the tadpole optic tectum is the ependymal radial glial cell. Radial glia serve both as a neuronal progenitor population (Noctor et al., 2001) and as a scaffold for cell migration, because of their unique morphology which spans the entire radial axis of the brain from ventricle to pia (Rakic, 1972). Interestingly, in the optic tectum, it is these radial glial cells, with their endfeet extending into the retinorecipient stratum opticum, that express gradients of guidance cues like ephrins and Wnt3 that are fundamentally responsible for topographic mapping of retinal axon terminals (Drescher et al., 1995; Braisted et al., 1997; Schmitt et al., 2006). Thus understanding the dynamic properties of these cells offers important new insights into the mechanisms underlying the development of the visual system.

We found that tectal radial glia in vivo exhibited functional calcium signaling and rapid structural remodeling similar to that reported in vitro for Bergmann glia and astrocytes. Their processes formed close appositions with tectal synapses. Visual stimulation, through NMDA receptor (NMDAR)-dependent synaptic activation in the tectum, modulated the rates of their calcium transients and structural rearrangements, revealing that radial glia do not merely serve as a passive structural scaffold, but actively interact with retinal ganglion cell (RGC) axons by dynamically responding to neuronal activity and transmitter release.

\section{Materials and Methods}

Electroporation. Glial cells of albino stage 46 Xenopus laevis tadpoles were transfected with a construct encoding farnesylated enhanced green fluorescent protein (EGFP-F) $(0.5 \mu \mathrm{g} / \mu \mathrm{l})$ by electroporation of both tectal 
lobes. Glass micropipettes were made from borosilicate capillaries (Sutter) pulled on a PC-10 puller (Narishige). Pipettes were filled with plasmid solution and attached to a custom-made pressure-injection system. The pipette tip was gently broken to prevent clogging. Plasmid solution was injected into the ventricle by pressure-injection. Current was delivered via platinum plate electrodes connected to a SD-9 stimulator (Grass Instruments), to which a $3 \mu \mathrm{F}$ capacitor was connected in parallel. The two plates of the electrode were placed on either side of the tectal lobe and three pulses of current $(30 \mathrm{~V}, 1.6 \mathrm{~ms})$ were delivered across the lobe in both directions. The pipette and the electrodes were held by two Narishige micromanipulators. A dissection microscope (Olympus SZ51) was used to perform the manipulations. Electroporated tadpoles were placed in bowls containing fresh solution for later screening for EGFP-F expression.

To demonstrate RGC-glia contacts, coelectroporation of plasmids encoding yellow fluorescent protein (YFP) $(1 \mu \mathrm{g} / \mu \mathrm{l})$ and synaptophysin tagged with GFP (Syp-GFP) $(1 \mu \mathrm{g} / \mu \mathrm{l})$ was performed in the eye of stage 44 tadpoles. At stage 46, whole brain electroporation was then performed using mCherry plasmids $(1 \mu \mathrm{g} / \mu \mathrm{l})$. Imaging was done when the tadpoles reached stage 48 .

Immunostaining of sections. Horizontal sections through tadpole heads were cut at $12 \mu \mathrm{m}$ thickness using a cryostat and mounted directly onto microscope slides. Slides were dried at $37^{\circ} \mathrm{C}$ for $30 \mathrm{~min}$, and then incubated in PBS/0.3\% Triton X-100 two times for $5 \mathrm{~min}$. They were further blocked for $1 \mathrm{~h}$ in blocking solution (5\% NGS/1\% BSA/PBS/0.03\% Triton $\mathrm{X}-100$ ) before incubating in primary antibody (Vimentin ascites, 1:50 and SV2 antibody, 1:1000 from Developmental Studies Hybridoma Bank, University of Iowa, Iowa City, IA) for $2 \mathrm{~h}$ at room temperature, washed 4 times for 10 min each with PBS/Triton $0.3 \%$ and then incubated in the secondary antibody (Alexa 488- or Alexa 555-tagged antibodies, Invitrogen) for $1 \mathrm{~h}$ at room temperature. Slides were then washed 3 times with PBS and mounted in glycerol-based mounting media. Digital images were collected on a Zeiss Axiovert S100TV microscope at 20X [numerical aperture (NA) 0.5, Plan-NEOfluor] with a cooled CCD camera (Optronics).

Whole-mount immunostaining. Tadpoles, anesthetized by immersion in $0.2 \% \mathrm{MS} 222$, were fixed overnight at $4^{\circ} \mathrm{C}$ in $4 \%$ paraformaldehyde in $0.1 \mathrm{M}$ phosphate buffer and rinsed in $0.1 \mathrm{M}$ phosphate buffer. Brains were dissected out, incubated in blocking solution at $4^{\circ} \mathrm{C}$ on a shaker for at least $30 \mathrm{~min}$ and then incubated with Vimentin or SV2 antibodies (1:200) for $24 \mathrm{~h}$ at $4^{\circ} \mathrm{C}$ on the shaker. The brains were washed 3 times for $30 \mathrm{~min}$ with blocking solution followed by a fourth wash overnight in blocking solution. Brains were then incubated in Alexa 555-conjugated secondary antibody (Invitrogen) overnight at $4^{\circ} \mathrm{C}$ on the shaker. Brains were rinsed 3 times for $30 \mathrm{~min}$ in $0.1 \mathrm{M}$ phosphate buffer followed by a fourth wash overnight in phosphate buffer at $4^{\circ} \mathrm{C}$ on the shaker. Whole mounts were imaged immediately afterward on the two-photon microscope at $990 \mathrm{~nm}$ excitation using an Olympus UIS2 $20 \times$ objective.

SV2-GFP pixel colocalization analysis. The SV2-GFP pixel colocalization analysis was done using ImageJ software. Red (SV2) and green (GFP) channel $z$-series stacks were thresholded just at the level above random background noise and the logical "AND" function was used to generate a pixel colocalization image. A control shifted colocalization image was also created by shifting the red stack by $5 \mu \mathrm{m}$ in the $z$-direction and performing the logical AND function with the green image. A twotailed paired $t$ test was used to analyze the areas of pixel colocalization for matched versus shifted colocalization images. Three-dimensional renderings were made using Imaris software (Bitplane).

Measurement of calcium transients. The calcium indicator Oregon Green 488 Bapta-AM (OGB-AM, Invitrogen) was suspended in $20 \%$ Pluronic in DMSO (50 $\mu \mathrm{g}$ in $4 \mu \mathrm{l}$ ) and then added at $10 \%(\mathrm{v} / \mathrm{v})$ to $\mathrm{MBSH}$ medium for pressure injection through a glass micropipette into the ventricle of the optic tectum in stage 48 tadpoles. Imaging was performed $\sim 2 \mathrm{~h}$ after injection. In a small number of cases $250 \mu \mathrm{M} 1,1^{\prime}$-dioctodecyl$3,3,3^{\prime}, 3^{\prime}$-tetramethylindo-carbocyanine (DiI) in ethanol was coinjected with OGB-AM to permit visualization of the labeled glial cell morphologies. Intracellular calcium transients were visualized in a single optical section at $\sim 0.8 \mathrm{~s}$ intervals on the two-photon microscope at $920 \mathrm{~nm}$. For spontaneous calcium transients experiments, animals were immobilized by injection with $2.5 \mathrm{~mm}$ D-tubocurare and imaged for $2 \mathrm{~min}$. For phar- macological treatment experiments, paralyzed animals were imaged during a $2 \mathrm{~min}$ baseline and then treated for $40 \mathrm{~min}$ in $10 \mu \mathrm{M} \mathrm{MK801,400 \mu \textrm {M }}$ L-NMMA (NG-monomethyl-L-arginine acetate) or control buffer and imaged again for $2 \mathrm{~min}$. For visually evoked calcium transients, after 3.33 min of baseline imaging, visual stimulation was performed by sequential flashing of an array of green light-emitting diodes (LEDs) at $1 \mathrm{~Hz}$ for 2 $\mathrm{min}$ and tadpoles were imaged again for $3.33 \mathrm{~min}$. Calcium transients in individual cells were analyzed using custom Matlab (MathWorks) programs that calculated the intensity of each pixel in a defined circular region-of-interest (20 pixels diameter) for every time point. Measurements of fluorescence intensity were normalized to the mean intensity of each cell over the entire imaging session. Calcium transients attaining intensities $>2$ SDs from the mean were counted for analysis. A two-tailed paired $t$ test was used to compare fractions of cells exhibiting transients before and after treatment.

Electrophysiology. Brains from stage 47-48 albino Xenopus laevis tadpoles were extracted in HEPES-buffered extracellular saline (in mм: 115 $\mathrm{NaCl}, 2 \mathrm{KCl}, 3 \mathrm{CaCl}_{2}, 1.5 \mathrm{MgCl}_{2}, 10$ HEPES, 10 glucose, 0.005 glycine, 10 $\mu \mathrm{M}$ DNQX, and $100 \mu \mathrm{M}$ picrotoxin, $\mathrm{pH}$ 7.3; osmolarity, $255 \mathrm{mOsm}$ ) and butterflied to expose the ventricular surface of the optic tectum. Brains were then pinned to a submerged block of Sylgard in a recording chamber and maintained at room temperature $\left(\sim 25^{\circ} \mathrm{C}\right)$ with continuous perfusion of external saline. To access the tectal cells, the ventricular membrane of the tectum was carefully disrupted using a broken glass pipette.

Cells were visualized using an Olympus BX51WI light microscope with a $60 \times$ (Olympus LUMPLFL 0.9NA) water-immersion objective, in combination with a CCD camera. Enhanced green fluorescent protein (EGFP)-expressing radial glia were identified morphologically using fluorescence, and recordings were obtained after switching to differential interference contrast optics. EGFP-glia and untransfected neurons were further classified by plotting current-voltage relationships from -60 to $+50 \mathrm{mV}$ in $10 \mathrm{mV}$ steps. Whole-cell voltage-clamp recordings were made using glass micropipettes (4-7 M $\Omega$ ) filled with Cs-MeSO4 intracellular saline (in mm: 100 Cs- $\mathrm{MeSO}_{4}, 10 \mathrm{TEA}-\mathrm{Cl}, 2 \mathrm{NaCl}, 1.5 \mathrm{MgCl}_{2}, 20$ HEPES, 0.5 EGTA, 2 ATP, and 0.3 GTP, pH 7.3; osmolarity, 255 mOsm). Electrical signals were measured with an Axopatch 200B (Molecular Devices), digitized at $5 \mathrm{kHz}$ and acquired using pClamp 8 software. Membrane potential in the figures was not adjusted to compensate for a 3.4 $\mathrm{mV}$ predicted liquid junction potential. NMDA $(100 \mu \mathrm{M})$ in external solution was locally puffed from a glass micropipette using $100 \mathrm{~ms}$ pressure pulses at the cell soma via a Picospritzer III (Parker). In some experiments, $100 \mu \mathrm{M}$ CPP was present in the bath solution as indicated. All drugs were purchased from Tocris Bioscience. Data were analyzed using ClampFit software (Molecular Devices).

Dynamic imaging protocol. In vivo two-photon microscopy of radial glia was performed using an Olympus FV300 confocal microscope custom-converted for multiphoton imaging equipped with a MaiTai-BB Ti:sapphire femtosecond pulsed laser. Images were acquired on a PC using Fluoview software (version 5.0). Stage 48 albino Xenopus laevis tadpoles were electroporated as described above to express EGFP-F. At the beginning of the imaging procedure, animals were immobilized by caudal injection of $2.5 \mathrm{~mm}$ D-tubocurare. To visualize motility, cells were imaged over $30 \mathrm{~min}$, with a total of 7 images taken in $5 \mathrm{~min}$ intervals. For activity blockade experiments, animals were first imaged $30 \mathrm{~min}$ for a baseline, after which time they were immersed in a bath of $10 \mu \mathrm{M}$ MK801, $400 \mu \mathrm{M}$ L-NMMA, $40 \mu \mathrm{M}$ GYKI-54266 or control buffer for at least 40 min, and were finally imaged a second time for another 30 min imaging sequence. Three images were taken in each $30 \mathrm{~min}$ interval, one image every $15 \mathrm{~min}$. For the NO rescue experiment animals was immersed in a bath of $10 \mu \mathrm{M}$ MK801 after receiving a ventricular injection of $1 \mathrm{~mm}$ DetaNONOate. For the visual stimulation experiments, the same protocol as drug treatment was followed but the $40 \mathrm{~min}$ bath application was replaced by $5 \mathrm{~min}$ of visual stimulation.

Analysis of dynamics. Maximum intensity projections of two-photon $z$-series stacks over time were aligned by using the Stackreg macro (http:// bigwww.epfl.ch/thevenaz/stackreg/) for ImageJ (http://rsbweb.nih.gov/ ij/). Glial motility was analyzed on these aligned image series using custom Matlab programs that performed sequential image edge detection followed by fixed radius dilation ( 8 pixel radius) of identified edges. 
The areas of change in added and lost pixels between dilated images in sequential time points were measured. The motility index of a cell was defined as the mean difference in pixel overlap for sequential time points normalized to the mean number of labeled pixels at all time points.

Individuals branch dynamics were measured using the ImageJ software segmented line drawing function. Ten random branches in each cell were picked by taking every tenth branch encountered along the cell profile. Branches were classified for each time point as elongating, retracting or stable (changing in length by $<1 \mu \mathrm{m}$ ) based on length changes between time points.

For visual stimulation analysis, cells were divided in two sections: the outer one-third of the neuropil and the inner two-thirds. The Matlab macro described above was independently applied to each section.

\section{Results}

Radial glia form a regular radial array across the tectal neuropil

To visualize the radial glia, we performed "whole brain" electroporation on stage 46 Xenopus tadpoles by injecting into the brain ventricle a plasmid encoding EGFP-F under the control of the strong CMV promoter. Electroporation electrodes were positioned on the surface of the intact tadpole spanning the entire brain. Because the somata of the radial glia line the ventricle, these cells are highly susceptible to electroporation by this approach. Membranetargeting EGFP-F provided excellent morphological detail of the numerous fine processes of the glial cells, allowing 3-dimensional reconstruction of these cells in the living tadpole using twophoton optical sectioning. Within $12 \mathrm{~h}$ after electroporation, bright green radial glia could be detected which contin-

ued to increase in fluorescence intensity, peaking after $\sim 2 \mathrm{~d}$ of expression at stage 48 (Fig. $1 \mathrm{~B}$ ). The radial glia have a characteristic triangular cell body shape, which distinguishes them from the pear-shaped somata of the tectal neurons found directly lateral to the glial cells. The glia extend a long main process dorsolaterally within the tectum which emits many fine filopodia, particularly within the lateral neuropil of the tectum, giving them the appearance of a bottle-brush (Fig. $1 C)$. Their endfeet lie on the lateral pial surface of the optic tectum. We found that these morphologically identifiable radial glia specifically expressed high levels of the classic radial glial intermediate filament protein vimentin (Fig. 1D). Vimentin immunostaining in cryostat sections (Fig. $1 E$ ) and brain whole mounts (Fig. $1 F$ ) reveals that the radial glia form a regular, radial array throughout the optic tectum with their endfeet effectively tiling the entire tectal neuropil at the pial surface. This regular distribution, combined with their highly bushy morphology within the neuropil is ideal to permit the radial glia to interact extensively with ingrowing axons and tectal synapses.
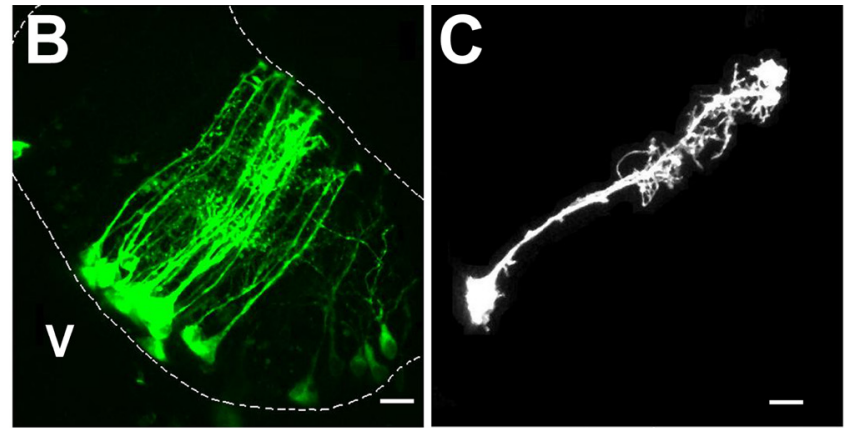
whole mount reveals a regular array of glial endfeet tiling the tectal neuropil where RGC axons innervate the tectum. Scale bars: $\boldsymbol{B}, \boldsymbol{D}, 15 \mu \mathrm{m} ; \boldsymbol{C}, 7 \mu \mathrm{m} ; \boldsymbol{E}, \boldsymbol{F}, 30 \mu \mathrm{m}$. V, ventricle.

Tectal radial glial processes target synaptic sites in the tectum Radial glia extend the majority of their filopodia within the neuropil area (Fig. 2A,B). Rybicka and Udin (1994) demonstrated glial profiles apposed to synapses in electron micrographs of adult Xenopus tectum. To determine whether radial glia interact with tectal synapses in tadpoles, we more closely examined radial glial morphology in tectal whole mounts immunostained for the presynaptic vesicle protein SV2 (Fig. 2C). Anti-SV2 staining labels all presynaptic sites in the optic tectum and densely labels the neuropil. Because the two-photon microscope is unable to completely resolve individual objects below the scale of a synaptic terminal, presynaptic terminals that are closely apposed to glial processes will appear colocalized. We therefore measured voxel colocalization as a reflection of apposition of EGFP-F-labeled glial processes with SV2-labeled puncta in multiple optical sections through the tectal whole mounts (Fig. 2C,D). To determine purely random overlap due to the high density of SV2 puncta we performed matched analyses in which the SV2 channel was shifted $5 \mu \mathrm{m}$ out of alignment with the GFP channel along the $z$-dimension, thereby preserving the spatial statistics of the im- 

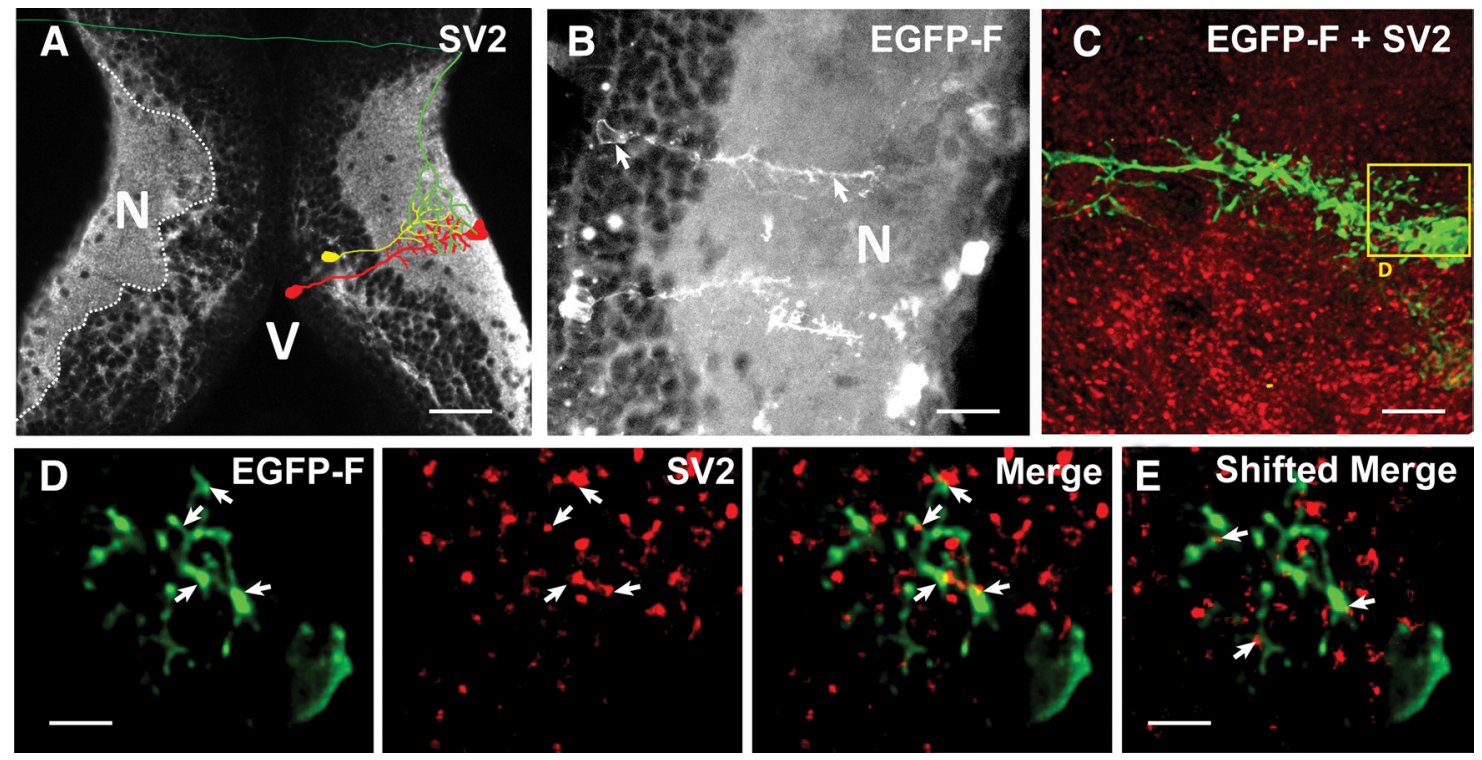

Figure 2. Radial glial processes contact synapses in the optic tectum. $\boldsymbol{A}$, Schematic of the main tectal cell types overlaid on an horizontal section through the optic tectum: glial cell (red), tectal neuron (yellow) and RGC axon (green). The neuropil (N) area is revealed by immunostaining for the synaptic vesicle marker SV2. B, Tectal section shows bushy EGFP-F-labeled glial processes in the neuropil. C, z-Projection of SV2 immunostained Xenopus brain whole mount in which there is a glial cell expressing EGFP-F (box indicates the high-magnification sections in D). D, Single optical section shows that EGFP-F-labeled processes are apposed to SV2-positive synaptic puncta (arrowheads). $\boldsymbol{E}$, Example of reduced colocalization observed when the red and green images are offset by $5 \mu \mathrm{m}$ in the $z$-axis ( $N=4$ whole mounts). Scale bars: $\boldsymbol{A}, 40 \mu \mathrm{m} ; \boldsymbol{B}, \boldsymbol{C}, 15 \mu \mathrm{m} ; \boldsymbol{D}, 10 \mu \mathrm{m}$. V, Ventricle; N, neuropil.

ages but removing true appositions (Fig. 2 E). Consistent with the presence of neuron-glia associations at synapses, EGFP-F-labeled radial glial processes exhibited significantly greater than chance appositions to SV2 puncta ( $1.47 \pm 0.082$-fold more voxel colocalization compared with shifted images, $p<0.01$ by Student's $t$ test).

\section{Radial glial processes contact retinal ganglion cell synapses} The tectum is a multimodal sensorimotor nucleus that receives inputs from numerous brain regions. We wanted to know whether synapses formed by RGC axons in the optic tectum also received glial contacts. To identify RGC terminals, we electroporated the contralateral retina with a plasmid mixture encoding YFP to visualize the entire axonal arbor and Syp-GFP, which labels presynaptic sites (Ruthazer et al., 2006) (Fig. 3A). In the same animals, whole brain electroporation to express mCherry in tectal cells was performed $1 \mathrm{~d}$ later (Fig. $3 A$ ). In contrast to experiments in which SV2 labeling was used to label all synapses in the tectum, the probability of random Syp-GFP contacts with glial processes is very low. Analysis of optical sections through these animals revealed numerous examples of radial glial filopodia associated with Syp-GFP-positive presynaptic sites on RGC axons (Fig. $3 B, C$ ). These results suggest that tectal glia are capable of interacting directly with retinotectal synapses.

Neuronal-activity-dependent calcium transients in radial glia If radial glia in the Xenopus optic tectum function like astrocytes in the mammalian forebrain, neurotransmitter release would be predicted to drive an intracellular calcium increase in some radial glial cells, indicating that like astrocytes, they are capable of responding to neural activity (Verkhratsky and Kettenmann, 1996; Pasti et al., 1997; Haydon, 2001). We bulk-loaded radial glial cells with the fluorescent calcium indicator Oregon Green Bapta (OGB), by injection of the cell-permeant acetoxymethyl (AM) ester of OGB (OGB-AM) into the ventricle of intact tadpoles. Because the ependymal radial glial cell somata line the ventricular surface, and the mature neuronal cell bodies are buried deeper within the tectum away from the periventricular zone, this technique results in highly selective OGB loading of radial glial cells (Fig. 4A). To verify that only radial glia were loaded by this method, in a small number of cases we coinjected dil together with OGB-AM into the ventricle (Fig. $4 B$ ). The diI brightly labeled the plasma membrane of all cells with which it came in contact, permitting us to confirm that only morphologically identifiable radial glia were loaded by this injection method. To measure calcium signals, a single optical section through the tectum was imaged at $0.8 \mathrm{~s}$ intervals over at least $2 \mathrm{~min}$ (Fig. $4 C$ ). Calcium transients were observed in a majority of OGB-loaded stage 48 tadpoles. These calcium transients lasted between 5 and $15 \mathrm{~s}$ (Fig. 4D), similar to those observed in mammalian astrocytes (Pasti et al., 1997).

To investigate whether the glial calcium transients reflected a response to synaptic transmission, we examined the glial calcium signal in tadpoles treated for 40 min with $10 \mu \mathrm{M}$ MK801, a noncompetitive NMDAR antagonist that is taken up through the skin by intact tadpoles and effectively blocks NMDAR-mediated synaptic transmission in the tectum when applied in the rearing solution (Ruthazer et al., 2003). We found that tadpoles exhibiting calcium transients before drug treatment showed a significant reduction in the number of transients after MK801 treatment, whereas no such reduction was observed for tadpoles treated for $40 \mathrm{~min}$ in control buffer (Fig. 4E, F,H). These results demonstrate that glial calcium transients respond to NMDAR activation. However, these data cannot distinguish between direct effects of MK801 on putative glial NMDARs versus effects on their neighboring neurons, which could release a distinct intercellular signal to act on nearby glia in response to NMDAR activation.

To further explore this latter possibility, we tested whether the diffusible neurotransmitter nitric oxide $(\mathrm{NO})$ could mediate glial activation. NADPH diaphorase staining to reveal NO synthasepositive cells labeled a population of neurons but not radial glia in 

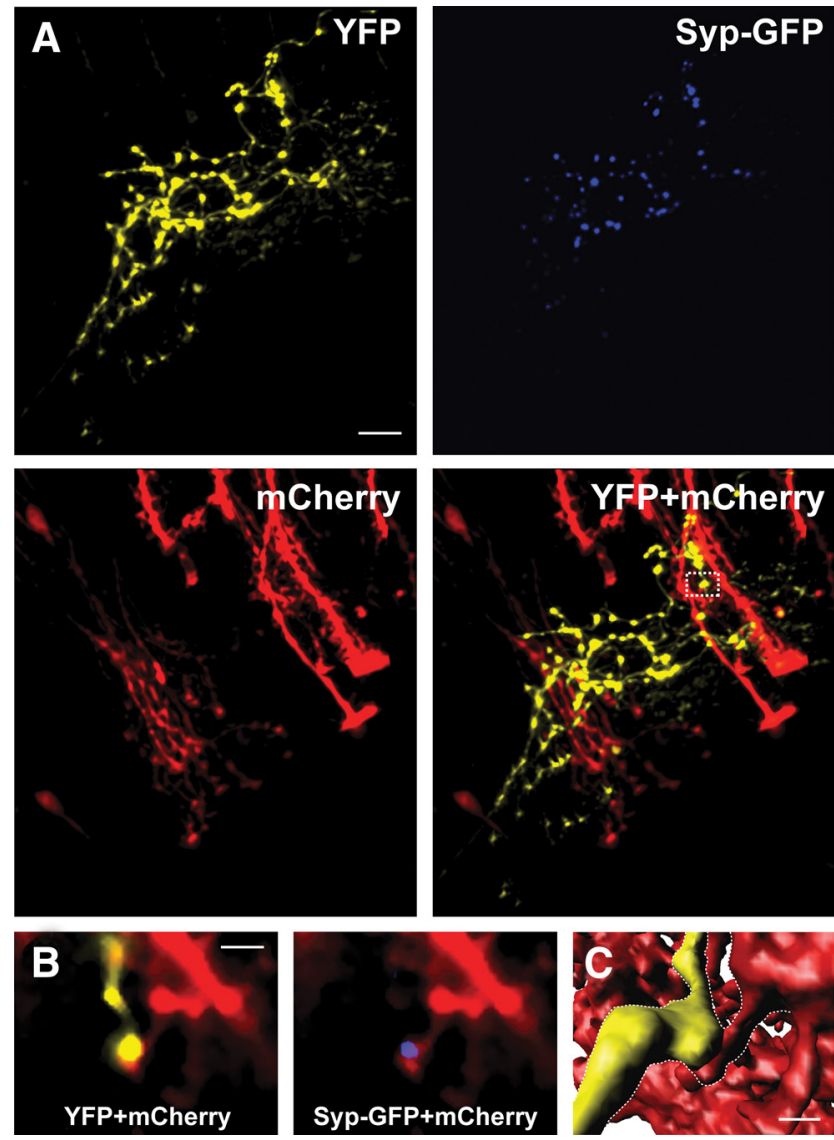

Figure 3. Radial glial processes contact retinotectal synaptic sites. $\boldsymbol{A}, \mathrm{z}$-Projections of RGC axon labeled with YFP (top left), coexpressing Syp-GFP to reveal presynaptic sites (top right), radial glia expressing $m$ Cherry in the same animal (bottom left), and YFP axon with radial glia expressing $\mathrm{mCherry}$ (bottom right). $\boldsymbol{B}$, Higher-magnification single optical section from $A$ (white square) to demonstrate contact between the RGC axon and glial process (left) at a Syp-GFP punctum (right). $C$, Three-dimensional reconstruction of the YFP $+m$ Cherry image in B. Scale bars: $\boldsymbol{A}, 10 \mu \mathrm{m} ; \boldsymbol{B}, 5 \mu \mathrm{m} ; \boldsymbol{C}, 3 \mu \mathrm{m}$.

the tectum (data not shown; Cogen and Cohen-Cory, 2000). NO synthesis is known to be dependent on calcium entry into neurons via NMDARs, making it a good candidate to mediate neuron-glial signaling (Bredt and Snyder, 1992; Zhuo et al., 1999; Metea and Newman, 2006). Bathing tadpoles in $400 \mu \mathrm{M}$ L-NMMA to block NO synthesis considerably reduced the frequency of calcium transients in glial cells both compared with a baseline period before drug application and to control animals (Fig. $4 E, G, H$ ). These results suggest that $\mathrm{NO}$ is an intercellular effector of NMDAR activation which causes an elevation in intracellular calcium concentration in neighboring tectal glia.

\section{Tectal radial glia in tadpoles do not express NMDARs}

Could glial NMDARs still play a permissive role in this process? NMDAR expression varies with glial cell type, brain area and developmental stage, with some glial cells reported to lack NMDARs entirely (Lipton, 2006; Verkhratsky and Kirchhoff, 2007; Serrano et al., 2008). To determine which tectal cells express NMDARs, we performed in situ hybridization against the NR1 subunit of the NMDAR on 48 stage tadpole brain sections. The NR1 subunit is obligatory for formation of a functional NMDAR. As expected, intense hybridization was observed in the neuronal cell layers of the optic tectum. In contrast, no labeling was detected in glial cell layer lining the ventricle (Fig. $5 A$ ). It is
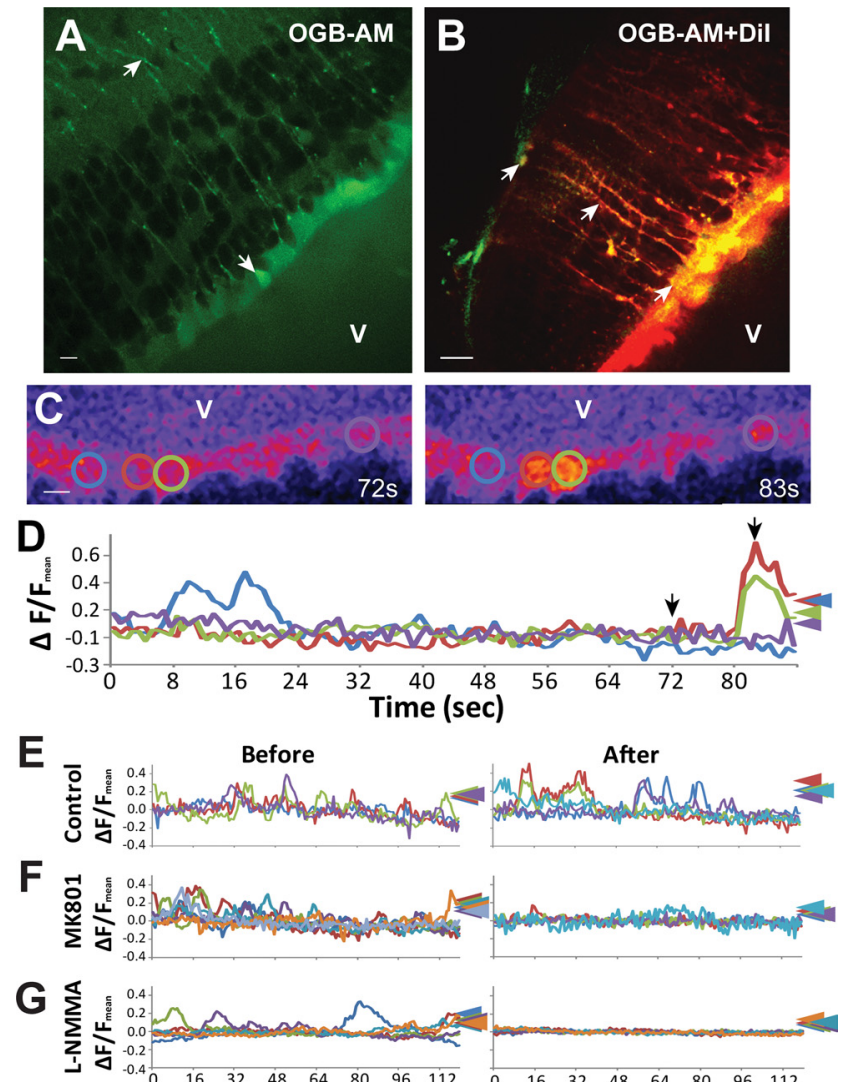

$\mathbf{F}$

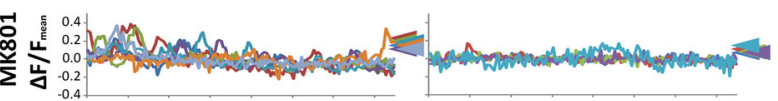

G
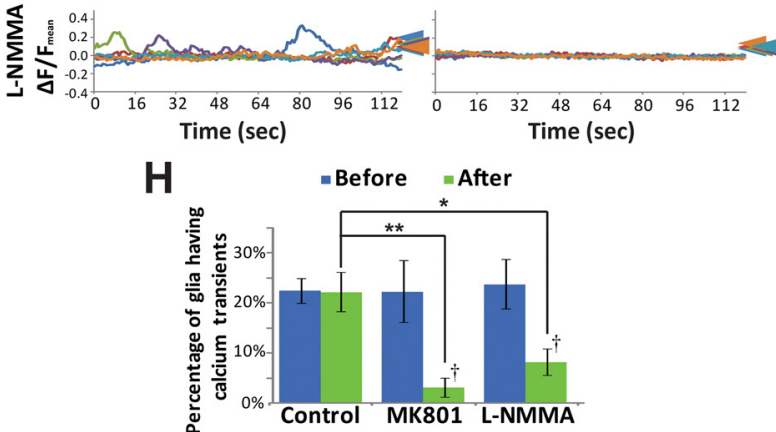

Figure 4. Modulation of tectal calcium transients by NMDAR activation and NO signaling. $A$, Single two-photon optical section through the optic tectum showing radial glia somata labeled by ventricular injection of OGB-AM. $B$, Morphology of radial glia visualized by ventricular injection of $0 \mathrm{~GB}-\mathrm{AM}+250 \mu \mathrm{m}$ Dil. C, Pseudocolored $\mathrm{OGB}$ calcium signal in tectal glia somata. $D, \Delta F / F_{\text {mean }}$ of the fluorescence in 4 different glia indicated by the colored circles in C. $E-G, \Delta F / F_{\text {mean }}$ from all responding glial cells from two-photon optical sections in different animals before and after bath application of control buffer, $10 \mu \mathrm{M}$ MK801 or $400 \mu \mathrm{m} \mathrm{L-NMMA.}$ Arrowheads on right indicate 2 SD above the mean. $\boldsymbol{H}$, Percentage of glia per optical section exhibiting calcium transients before and after bath application of control buffer $(N=6)$, MK801 $(N=5)$, or L-NMMA $(N=7)$. v, Ventricle. ${ }^{*} p<0.05 ;{ }^{* *} p<0.01$, ANOVA; ${ }^{\dagger} p<0.05$, two-tailed paired $t$ test. Scale bars: $\boldsymbol{A}, \boldsymbol{C}, 7 \mu \mathrm{m} ; \boldsymbol{B}, 25 \mu \mathrm{m}$. Error bars are SEM.

therefore unlikely that radial glia in the optic tectum express functional NMDARs.

To exclude the possibility that undetected low levels of NR1 message may be sufficient for radial glia to form functional NMDARs, we looked for functional NMDA-evoked currents in radial glia in stage 48 tadpoles by puffing NMDA onto tectal cells while recording in whole-cell voltage-clamp mode. Morphologically identified radial glia expressing GFP were targeted for recording, along with neurons in the same animals by patching cells in isolated brain preparations from electroporated animals. Brains were perfused in external solution containing $10 \mu \mathrm{M}$ DNQX and $100 \mu \mathrm{M}$ picrotoxin to prevent indirect activation of currents by released glutamate or GABA. Glial recordings were readily distinguishable from tectal neurons by their lack of a 

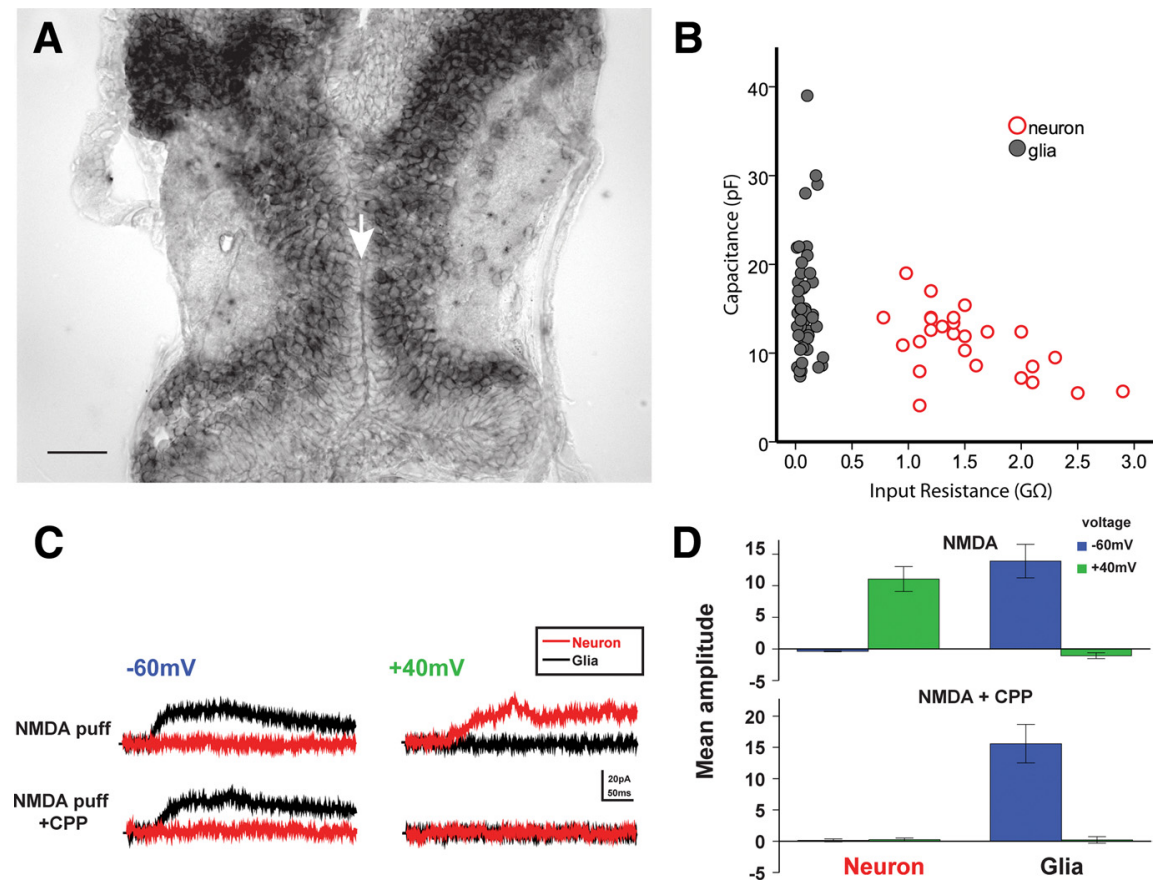

Figure 5. NMDARs are not expressed in radial glia. $\boldsymbol{A}$, In situ hybridization against NR1 mRNA in stage 48 tadpole brain section shows no staining of radial glial cell bodies that line the ventricle (arrow). $\boldsymbol{B}$, Morphologically identified radial glia cells were readily distinguishable from neurons based on overall larger capacitances and consistently lower input resistances in whole-cell recordings. C, Representative current traces of a neuron (red) and a glia (black) in response to a $100 \mathrm{~ms}$ puff of $100 \mu \mathrm{m}$ NMDA onto the cell clamped at $-60 \mathrm{mV}$ (left) and $+40 \mathrm{mV}$ (right) in absence (top) or in presence (bottom) of the NMDAR antagonist CPP (100 $\mu \mathrm{M})$. $D$, Mean response amplitudes generated in neurons (left) and glia (right) after an NMDA puff in the absence (top) or in presence (bottom) of (PP at different holding potentials. Because CPP blocks the classic NMDAR current in neurons, but not the outward current seen in hyperpolarized glia, this glial current is probably not mediated by NMDARs. Scale bar, $50 \mu \mathrm{m}$. Error bars are SEM.

voltage-sensitive sodium current (data not shown), higher membrane capacitance and low input resistance (Fig. 5B). Delivering a $100 \mathrm{~ms}$ puff of NMDA $(100 \mu \mathrm{M})$ onto cells clamped at $+40 \mathrm{mV}$ had no effect on glia whereas neurons responded with a long-lasting outward current that was blocked by the competitive NMDAR antagonist 3-(2-carboxypiperazin-4-yl) propyl-1phosphonic acid (CPP, $100 \mu \mathrm{M}$ ) (Fig. 5C,D). As predicted, at -60 $\mathrm{mV}$, neurons did not respond to the NMDA puff, because of the magnesium block. Curiously, at $-60 \mathrm{mV}$ glia responded to NMDA with an outward current that washed out over time (Fig. 5C,D). However, this current was not blocked by CPP, and therefore unlikely to be mediated by NMDARs. A similar NMDA-evoked current, also insensitive to NMDAR antagonists, has been described in human astrocytes where it has been attributed to an unidentified G-protein coupled receptor (Kondoh et al., 2001). Our ability to abolish this current by setting command potential to $+40 \mathrm{mV}$ demonstrates that radial glia can be effectively voltage-clamped despite their low input resistances. Although it remains formally possible that radial glia might exhibit NMDAR currents far from their somata that we failed to detect, the absence of CPP-sensitive currents in our glial recordings, together with the lack of NR1 message, suggests that tectal radial glia are unlikely to have functional NMDARs. These results indicate that any effects on glia of NMDAR blockade are most likely due to indirect action via neuronal NMDARs.

\section{Radial glia exhibit rapid structural remodeling}

Astrocytes in acute brain slices and slice cultures have been reported to exhibit rapid structural plasticity (Hirrlinger et al., 2004; Volterra and Meldolesi, 2005; Haber et al., 2006; Nestor et al., 2007; Nishida and Okabe, 2007; Lippman et al., 2008). In light of our finding that radial glial calcium dynamics exhibits a strong neural activity-sensitivity much like astrocytes, we wondered whether radial glia might also exhibit extensive structural motility in vivo that could potentially be influenced by neural activity. Indeed dramatic structural changes in microglia have been demonstrated in vivo, particularly in response to activation by focal injury (Davalos et al., 2005; Nimmerjahn et al., 2005).

We imaged tectal radial glia expressing EGFP-F in intact, stage 48 tadpoles, collecting one image every $5 \mathrm{~min}$ for $30 \mathrm{~min}$ (Fig. 6A-C). Surprisingly, the majority of filopodia extending from the main stalk of the radial glia exhibited dramatic motility, extending or retracting several micrometers during each 5 min interval (Fig. $6 B, C$; supplemental movies, available at www.jneurosci.org as supplemental material). In contrast to the dendritic arbors of tectal neurons, which grow and elaborate over time by the cumulative addition of new branches (Sin et al., 2002) the radial glia did not appear to become more complex over time, despite their remarkable degree of structural remodeling, suggesting that this motility serves a purpose other than growth.

\section{NMDAR activity-dependent rapid remodeling in radial glia}

We next investigated whether the rapid filopodial remodeling of glia, like the calcium transients, was sensitive to neuronal activity. EGFP-F-transfected glia in animals were imaged three times at 15 min intervals to reveal motility while minimizing phototoxicity and photobleaching (Fig. 7A). They were then exposed to MK801 $(10 \mu \mathrm{M})$ or control buffer in their rearing solution for $40 \mathrm{~min}$. Finally, the same cells were again imaged 3 times at 15 min intervals, with the drug still present in the imaging chamber during the second round of imaging.

Images were analyzed using a custom Matlab macro to measure the overall motility of each cell before and after treatment (see methods). The motility values of control animals before and after sham treatment were unchanged, demonstrating that the imaging protocol did not impact cell health (Fig. $7 B, G, L$ ). Interestingly, we found that blocking NMDARs with MK801 reduced the motility of treated cells to nearly half of their baseline values (Fig. $7 C, H, L$ ). A similar reduction was obtained using CPP (data not shown). The decrease in motility was specific to NMDAR inhibition and not due to an overall reduction in the tectal activity, because the AMPAR blocker, GYKI-54266 (40 $\mu \mathrm{M})$, caused only a small, nonsignificant reduction in glial dynamics (Fig. $7 D, I, L$ ). Consistent with our calcium imaging data, implicating $\mathrm{NO}$ as a mediator of neuron-glia communication in the tectum, bath application of $400 \mu \mathrm{M} \mathrm{L}-\mathrm{NMMA}$ for $40 \mathrm{~min}$ reduced glial motility by $\sim 25 \%$ (Fig. $7 E, J, L$ ). Furthermore, intraventricular injection of the NO donor molecule, DetaNONOate (1 mM), completely reversed the reduction in glial motility caused by MK801, suggesting that NO release may normally mediate the control of glial dynamics downstream of NMDAR activation (Fig. $7 F, K, L)$. 

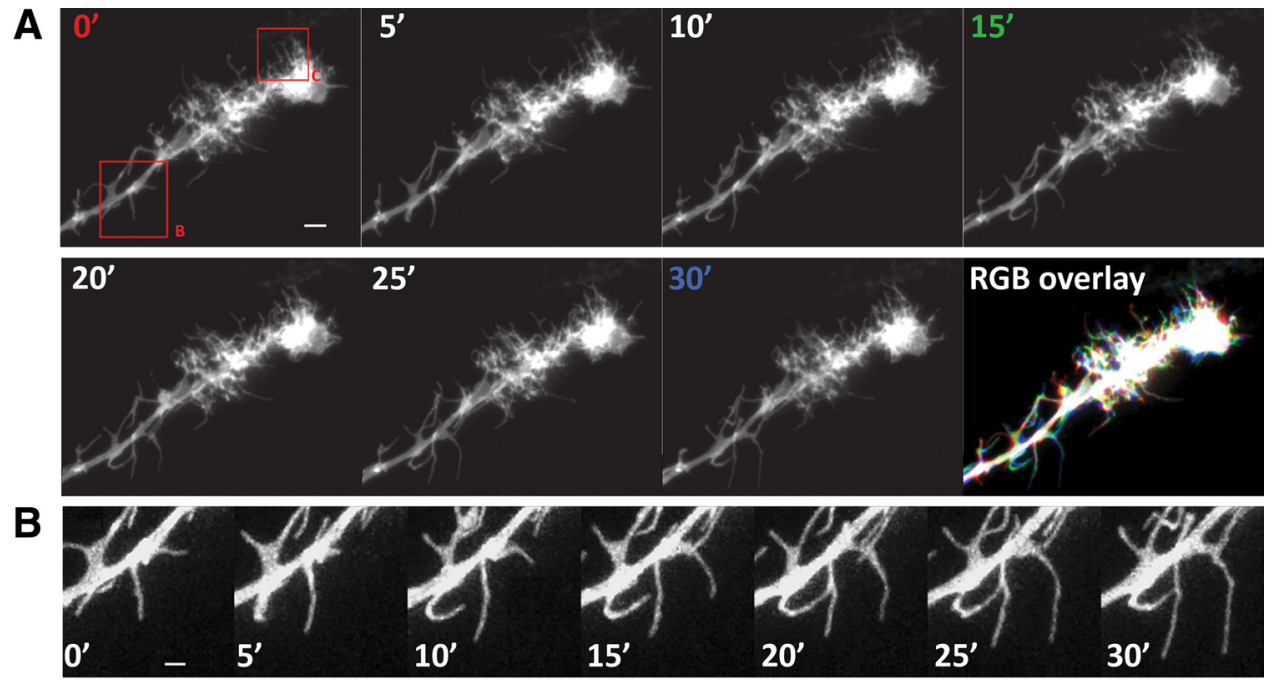

C

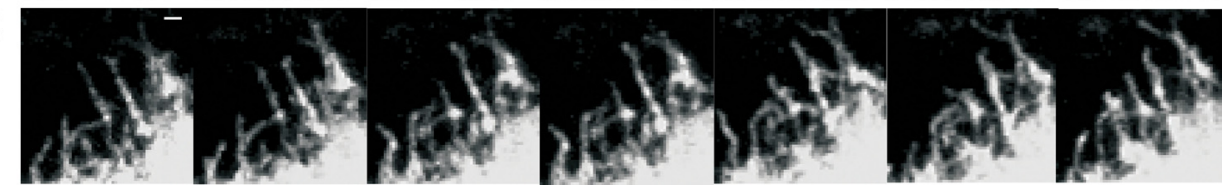

Figure 6. Radial glial processes exhibit rapid structural motility. $\boldsymbol{A}$, Time series of a glia expressing EGFP-F imaged in vivo at 5 min intervals. The RGB merge of the time points with the red, green and blue boxes demonstrates the degree of structural remodeling seen. $\boldsymbol{B}, \boldsymbol{C}$, Higher magnification of the two boxed regions in $\boldsymbol{A}$. Scale bars: $\boldsymbol{A}, 10 \mu \mathrm{m} ; \boldsymbol{B}, \boldsymbol{C}, 2 \mu \mathrm{m}$.

Our index of motility reflects changes in the structure of the entire cell over time. To understand how the changes in glial motility related to the behaviors of individual filopodial processes we determined the relative distributions of elongating, retracting and stable (changing by $<1 \mu \mathrm{m}$ per time point) filopodia in each of the treatment conditions. In control stage 48 tadpoles, $39 \pm$ $6 \%$ of branches elongated, $49 \pm 10 \%$ of branches retracted and $12 \pm 4 \%$ were stable (Fig. $7 M$ ). A significant shift favoring stable branches was observed in both the MK801 (46 $\pm 7 \%$ ) and L-NMMA (41 $\pm 4 \%$ )-treated groups (Fig. 7M). This shift was not seen after GYKI treatment or after the rescue of NO release in MK801-treated animals by DetaNONOate injection. These results reveal that process motility in radial glia in the optic tectum is strongly modulated by neuronal activity via neuronal NMDAR activation and subsequent NO signaling.

\section{Visual stimulation induces calcium transients and motility changes}

Because tectal glial processes appear to interact with retinotectal synapses (Fig. 3), we reasoned that visual stimulation should also regulate calcium transients and process motility. To examine the effect of visual stimulation on calcium transients, animals were dark adapted for at least $20 \mathrm{~min}$ before imaging and baseline measurements of calcium activity in the glia were obtained for 200 s. Very few transients were observed in dark adapted tadpoles. Visual stimulation was then provided using an array of green LEDs to deliver a simulated motion stimulus at $1 \mathrm{~Hz}$ (Sin et al., 2002) to the contralateral eye for $2 \mathrm{~min}$. After stimulation, calcium imaging was repeated for another $200 \mathrm{~s}$. A large increase in the fraction of tectal glia exhibiting calcium transients was observed (Fig. 8A, B).

We next asked whether glial motility was also affected by visual stimulation. We imaged baseline glial motility in darkadapted tadpoles for $30 \mathrm{~min}$. After applying the simulated motion stimulus to the tadpoles, we again imaged the radial glia for changes in motility. In contrast to pharmacological blockade of
NMDAR activation which blocks synapses throughout the optic tectum (Fig. $8 F$ ), visual stimulation should principally impact synapses in the retinorecipient outer layers of the optic tectum. We therefore measured motility in the outer one-third of the tectal neuropil, corresponding to the location of RGC inputs, and the inner two-thirds of the tectal neuropil independently. Indeed motility in the outer one-third (Fig. $8 \mathrm{C}$, blue) was on average enhanced by visual stimulation, whereas the inner two-thirds (Fig. 8C, pink) was unaffected. The differential motility in the outer and inner domains of the glial cells did not simply reflect a difference in overall sensitivity of these two regions to activity manipulations, as MK801 application significantly reduced motility across the entire cell (Fig. 8D).

\section{Discussion}

The in vivo imaging experiments in this study demonstrate that radial glial cells in the developing midbrain are remarkably responsive to changes in neural activity and sensory input. They exhibit activity-dependent calcium transients and rapid structural remodeling, both of which are regulated by neuronal NMDAR activation which in turn induces intercellular signaling through NO release. Furthermore, in the intact animal the dynamic structural remodeling of glia is also responsive to natural sensory stimuli, suggesting that patterned activity during topographic map development not only impacts neuronal connectivity and function directly, as has been appreciated for some time now (for review, see Huberman et al., 2008), but may also be able to act through the structural and functional modulation of neuron-glial interactions.

Radial glia perform a diverse set of critical functions in CNS development. In the retinotectal system, the radial glia are the cells that most prominently express the graded patterns of axon guidance molecules including ephrins and Wnt3 that guide the formation the retinotopic map in the optic tectum (Drescher et al., 1995; Braisted et al., 1997; Schmitt et al., 2006; Huberman et al., 2008). Our study now reveals that during the period when 
A

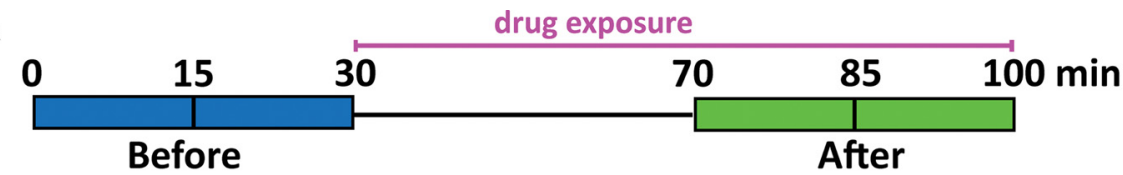
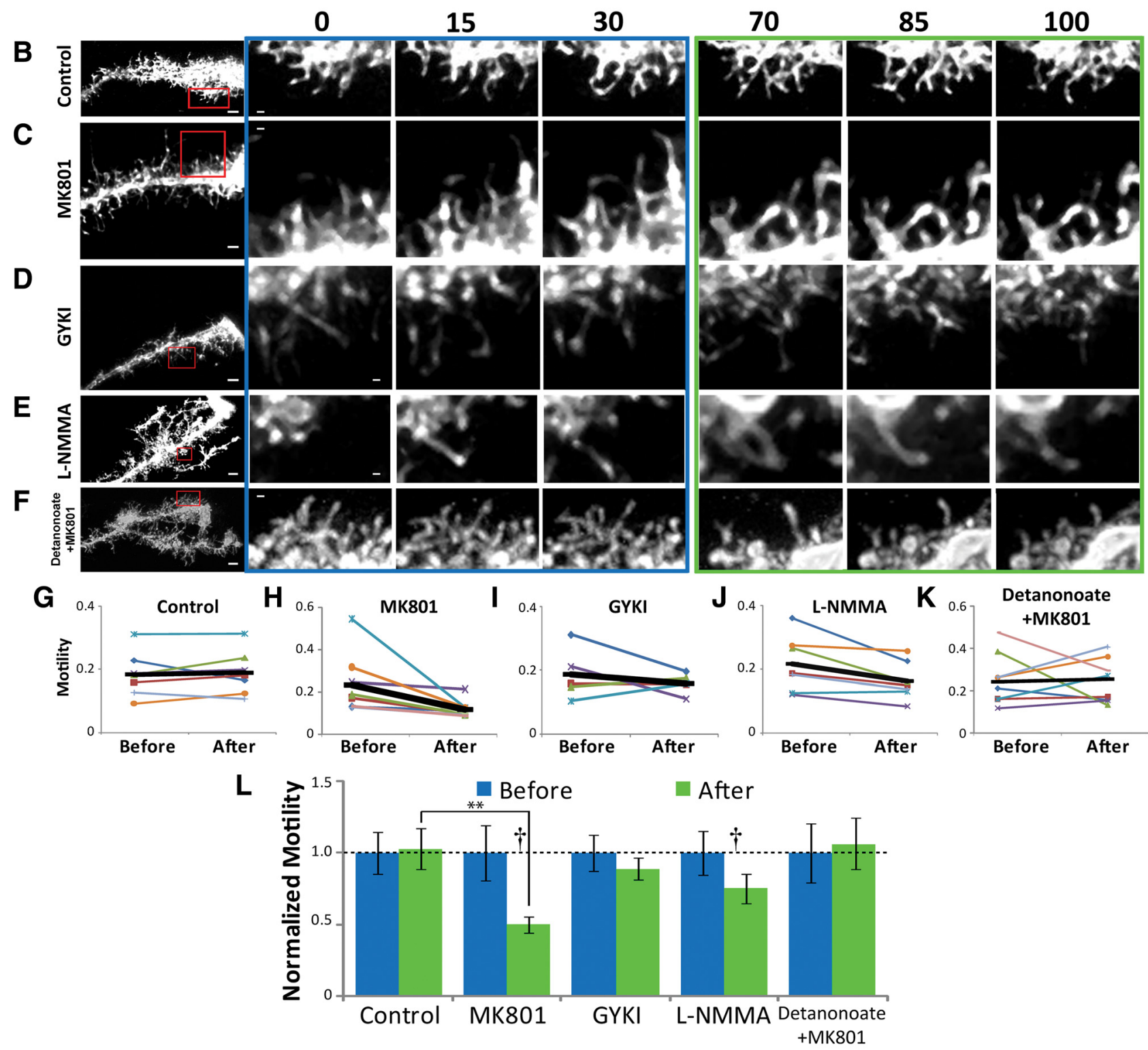

M astable aretracting aelongating

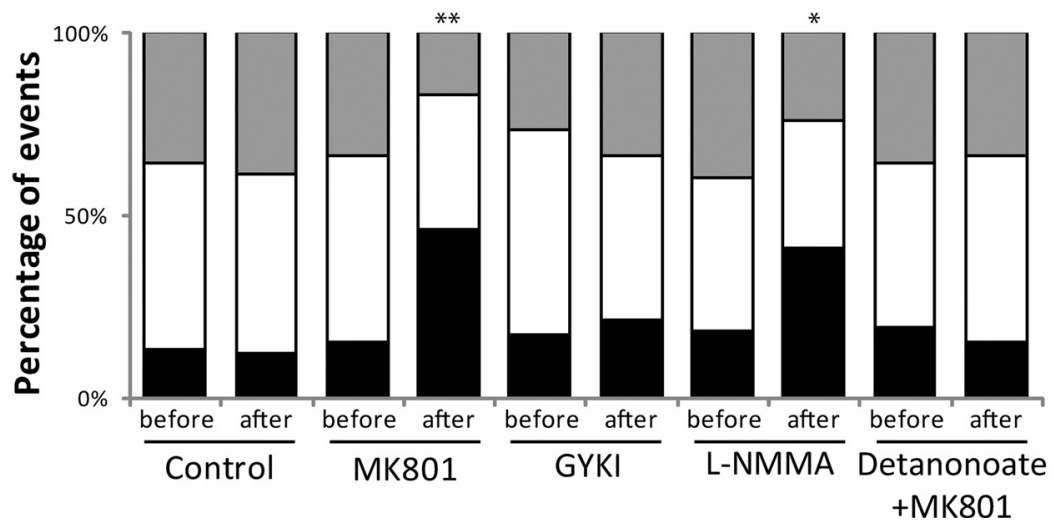

Figure 7. Rapid structural remodeling is regulated by neuronal NMDAR activation and NO signaling. $\boldsymbol{A}$, Schematic of the imaging protocol. $\boldsymbol{B}-\boldsymbol{F}$, Examples of 15 min interval time series z-projections of glia treated with control medium (B), MK801 (C), GYKI-54266 (D), L-NMMA (E), and DetaNONOate + MK801 (F). Cells were all expressing EGFP-F and imaged (Figure legend continues.) 
RGC axons are extending and refining their topographic projection in the optic tectum, guided by these glia-derived cues, the glia themselves are not only reaching out to contact the RGC axons but are also reacting to neural activity carried by these afferents.

The absence of NMDARs in these glial cells indicates that one or more additional molecules must mediate the NMDARactivated signaling cascade from neurons to glia. Potential candidates include glutamate, potassium, ATP, and nitric oxide. Glutamate released by presynaptic terminals could activate glial transporters, metabotropic glutamate receptors or AMPA receptors, which have been demonstrated, for example, on astrocytes and Bergmann glia (Yang et al., 2003; Fellin and Carmignoto, 2004; Bellamy and Ogden, 2005; Volterra and Meldolesi, 2005; Panatier et al., 2006a; Jourdain et al., 2007). We have provided evidence that NO mediates at least part of this intercellular signal. Neuronal NO synthesis is activated by calcium entry through NMDARs (Bredt and Snyder, 1992; Zhuo et al., 1999; Metea and Newman, 2006). The nitric oxide-regulated G-kinase has been reported to regulate of $\mathrm{Ca}$ transient generation (Willmott et al., 2000) and to alter cytoskeletal dynamics in cultured astrocytes (Borán and García, 2007), consistent with our findings in vivo.

What might be the purpose of this neuron-glia dialogue? Initially the rapid motility of the radial glia may improve the efficiency of axon guidance. The easiest way to present a gradient of guidance molecules would be to completely fill the target space with these cues, however Ephs and ephrins are membrane-associated molecules and Wnt3 is highly hydrophobic (Schmitt et al., 2006). Thus, the glial process extensions and retractions may permit frequent presentation of guidance cues to axons while still permitting adequate space for growth and remodeling. Later, as axons begin to form synaptic contacts onto tectal cell dendrites, activity-dependent mechanisms for map refinement, possibly including synaptic long-term potentiation and long-term depression (LTD), should become increasingly important. It has been reported that LTD in the Xenopus retinotectal system requires NO synthesis ( $\mathrm{Mu}$ and Poo, 2006), suggesting that glial dynamics, which we have shown in this study to be NO-regulated, may participate in LTD. In support of this idea, in cultured hippocam-

$\leftarrow$

(Figure legend continued.) in vivo. G-K, Motility analysis of all control $(N=7)(\mathbf{G})$, MK801 ( $N=$ 9) $(\boldsymbol{H}), \operatorname{GYKL}-54266(N=7)(\boldsymbol{I}), \mathrm{L}-\mathrm{NMMA}(N=7)(\boldsymbol{J})$, and DetaNONOate + MK801 $(N=9)(\boldsymbol{K})$ cells before and after treatment. Thick black lines represent group means. $L$, Relative motility for the different groups before and after treatment. $\boldsymbol{M}$, Distributions of elongating, retracting and stable filopodial behaviors for the different groups before and after treatment. Scale bars: $\boldsymbol{A}-\boldsymbol{F}$, left panel, $5 \mu \mathrm{m} ; \boldsymbol{A}-\boldsymbol{F}$, right panel, $0.5 \mu \mathrm{m} .{ }^{\dagger} p<0.05$, two-tailed paired $t$ test; ${ }^{*} p<0.05$; ${ }^{* *} p<0.01$, ANOVA with Bonferroni post hoc test. Error bars are SEM. pal slices, ephrin-A3 presented by motile astrocytic processes has been implicated in regulation of synaptic morphology and function by inducing spine retraction (Murai et al., 2003; Nestor et al., 2007). Alternatively, as synapses are weakened by LTD, glial processes may be recruited to help redirect the axon to a more appropriate partner. One possible mechanism by which glial activation could control axonal or dendritic remodeling could be through the activity-dependent regulation of adhesion molecules on glial surfaces. In cultured astrocytes, blocking spontaneous $\mathrm{Ca}^{2+}$ transients has been shown to dramatically reduce the expression of adhesion molecules such as cadherins by glial cells, consequently suppressing outgrowth of axonal and dendritic processes from adjacent neurons (Kanemaru et al., 2007).

Other important functions attributed to radial glia include their roles as neuronal progenitors (Noctor et al., 2001) and as scaffolds for neuronal migration (Rakic, 1972). Nitric oxide is an important negative regulator of neuronal precursor proliferation that has been shown to control the number of dividing cells in the Xenopus optic tectum during development (Peunova et al., 2001). Our finding that $\mathrm{Ca}^{2+}$ transients were dramatically reduced by inhibitors of NO synthase are consistent with studies in the 
cortex arguing that calcium waves in radial glia promote neuronal proliferation where they may help synchronize the cell cycle of these progenitor cells (Bittman et al., 1997; Weissman et al., 2004). Our data suggest a link between visual stimulusdriven $\mathrm{Ca}^{2+}$ activity in radial glia and NO production in the brain, offering a possible mechanism for activity-dependent control of neuronal proliferation.

Formation of new synapses also clearly involves glial participation. For example, astrocyte-secreted factors like thrombospondins promote normal CNS synaptogenesis (Christopherson et al., 2005). Manipulations that reduce astrocytic motility in hippocampal cultures have been reported to impair the conversion of transient dendritic protrusions into stable spines (Nishida and Okabe, 2007). It has also been proposed that glial interactions at synapses can modulate synaptic transmission and plasticity both by release of gliotransmitters and by regulation of extracellular potassium and transmitter uptake (Nedergaard et al., 2003; Volterra and Meldolesi, 2005; Jourdain et al., 2007; Theodosis et al., 2008). For example, astrocytes in the hypothalamus respond to lactation or acute dehydration, by rapidly and reversibly withdrawing the fine processes that envelope synapses in the supraoptic nucleus, thereby altering synaptic properties with ensuing behavioral consequences (Perlmutter et al., 1985; Panatier et al., 2006b; Wang and Hatton, 2009). The rapid structural dynamics of radial glia that we have observed may indicate that these forms of local modulation of function are able to occur with faster kinetics than had previously been anticipated. Finally, it is intriguing to speculate that in addition to participating in local synaptic modulation, the radial structure of the tectal glia may also permit them to integrate signals from different sensory modalities across tectal laminae.

Our data clearly demonstrate that radial glia in the developing optic tectum can respond both with enhanced calcium transients and dramatic structural plasticity to natural sensory stimulation. It will be important in future experiments to address the specific contributions of structural remodeling and Ca-signaling by the tectal radial glia to experience-dependent topographic map formation and plasticity.

\section{References}

Bellamy TC, Ogden D (2005) Short-term plasticity of Bergmann glial cell extrasynaptic currents during parallel fiber stimulation in rat cerebellum. Glia 52:325-335.

Bittman K, Owens DF, Kriegstein AR, LoTurco JJ (1997) Cell coupling and uncoupling in the ventricular zone of developing neocortex. J Neurosci 17:7037-7044.

Borán MS, García A (2007) The cyclic GMP-protein kinase G pathway regulates cytoskeleton dynamics and motility in astrocytes. J Neurochem 102:216-230.

Braisted JE, McLaughlin T, Wang HU, Friedman GC, Anderson DJ, O'leary DD (1997) Graded and lamina-specific distributions of ligands of EphB receptor tyrosine kinases in the developing retinotectal system. Dev Biol 191:14-28.

Bredt DS, Snyder SH (1992) Nitric oxide, a novel neuronal messenger. Neuron 8:3-11.

Christopherson KS, Ullian EM, Stokes CC, Mullowney CE, Hell JW, Agah A, Lawler J, Mosher DF, Bornstein P, Barres BA (2005) Thrombospondins are astrocyte-secreted proteins that promote CNS synaptogenesis. Cell 120:421-433.

Cogen J, Cohen-Cory S (2000) Nitric oxide modulates retinal ganglion cell axon arbor remodeling in vivo. J Neurobiol 45:120-133.

Davalos D, Grutzendler J, Yang G, Kim JV, Zuo Y, Jung S, Littman DR, Dustin ML, Gan WB (2005) ATP mediates rapid microglial response to local brain injury in vivo. Nat Neurosci 8:752-758.

Drescher U, Kremoser C, Handwerker C, Löschinger J, Noda M, Bonhoeffer F (1995) In vitro guidance of retinal ganglion cell axons by RAGS, a 25
$\mathrm{kDa}$ tectal protein related to ligands for Eph receptor tyrosine kinases. Cell 82:359-370.

Fellin T, Carmignoto G (2004) Neurone-to-astrocyte signaling in the brain represents a distinct multifunctional unit. J Physiol 559:3-15.

Haber M, Zhou L, Murai KK (2006) Cooperative astrocyte and dendritic spine dynamics at hippocampal excitatory synapses. J Neurosci 26:88818891.

Haydon PG (2001) Glia: listening and talking to the synapse. Nat Rev Neurosci 2:185-193.

Hirrlinger J, Hülsmann S, Kirchhoff F (2004) Astroglial processes show spontaneous motility at active synaptic terminals in situ. Eur J Neurosci 20:2235-2239.

Huberman AD, Feller MB, Chapman B (2008) Mechanisms underlying development of visual maps and receptive fields. Annu Rev Neurosci 31:479-509.

Jourdain P, Bergersen LH, Bhaukaurally K, Bezzi P, Santello M, Domercq M, Matute C, Tonello F, Gundersen V, Volterra A (2007) Glutamate exocytosis from astrocytes controls synaptic strength. Nat Neurosci 10: 331-339.

Kanemaru K, Okubo Y, Hirose K, Iino M (2007) Regulation of neurite growth by spontaneous $\mathrm{Ca}$ oscillations in astrocytes. J Neurosci 27:8957-8966.

Kondoh T, Nishizaki T, Aihara H, Tamaki N (2001) NMDA-responsible, APV-insensitive receptor in cultured human astrocytes. Life Sci 68:1761-1767.

Lippman JJ, Lordkipanidze T, Buell ME, Yoon SO, Dunaevsky A (2008) Morphogenesis and regulation of Bergmann glial processes during Purkinje cell dendritic spine ensheathment and synaptogenesis. Glia 56:1463-1477.

Lipton SA (2006) NMDA receptors, glial cells, and clinical medicine. Neuron 50:9-11.

Metea MR, Newman EA (2006) Calcium signaling in specialized glial cells. Glia 54:650-655.

Mu Y, Poo MM (2006) Spike timing-dependent LTP/LTD mediates visual experience-dependent plasticity in a developing retinotectal system. Neuron 50:115-125.

Murai KK, Nguyen LN, Irie F, Yamaguchi Y, Pasquale EB (2003) Control of hippocampal dendritic spine morphology through ephrin-A3/EphA4 signaling. Nat Neurosci 6:153-160.

Nedergaard M, Ransom B, Goldman SA (2003) New roles for astrocytes: redefining the functional architecture of the brain. Trends Neurosci 26:523-530.

Nestor MW, Mok LP, Tulapurkar ME, Thompson SM (2007) Plasticity of neuron-glial interactions mediated by astrocytic EphARs. J Neurosci $27: 12817-12828$.

Nimmerjahn A, Kirchhoff F, Helmchen F (2005) Resting microglial cells are highly dynamic surveillants of brain parenchyma in vivo. Science 308:1314-1318.

Nishida H, Okabe S (2007) Direct astrocytic contacts regulate local maturation of dendritic spines. J Neurosci 27:331-340.

Noctor SC, Flint AC, Weissman TA, Dammerman RS, Kriegstein AR (2001) Neurons derived from radial glial cells establish radial units in neocortex. Nature 409:714-720.

Panatier A, Theodosis DT, Mothet JP, Touquet B, Pollegioni L, Poulain DA, Oliet SH (2006a) Glia-derived D-serine controls NMDA receptor activity and synaptic memory. Cell 125:775-784.

Panatier A, Gentles SJ, Bourque CW, Oliet SH (2006b) Activity-dependent synaptic plasticity in the supraoptic nucleus of the rat hypothalamus. J Physiol 573:711-721.

Pasti L, Volterra A, Pozzan T, Carmignoto G (1997) Intracellular calcium oscillations in astrocytes: a highly plastic, bidirectional form of communication between neurons and astrocytes in situ. J Neurosci 17:7817-7830.

Perlmutter LS, Tweedle CD, Hatton GI (1985) Neuronal/glial plasticity in the supraoptic dendritic zone in response to acute and chronic dehydration. Brain Res 361:225-232.

Peunova N, Scheinker V, Cline H, Enikolopov G (2001) Nitric oxide is an essential negative regulator of cell proliferation in Xenopus brain. J Neurosci 21:8809-8818.

Rakic P (1972) Mode of cell migration to the superficial layers of fetal monkey neocortex. J Comp Neurol 145:61-83. 
Ruthazer ES, Akerman CJ, Cline HT (2003) Control of axon branch dynamics by correlated activity in vivo. Science 301:66-70.

Ruthazer ES, Li J, Cline HT (2006) Stabilization of axon branch dynamics by synaptic maturation. J Neurosci 26:3594-3603.

Rybicka KK, Udin SB (1994) Ultrastructure and GABA immunoreactivity in layers 8 and 9 of the optic tectum of Xenopus laevis. Eur J Neurosci 6:1567-1582.

Schmitt AM, Shi J, Wolf AM, Lu CC, King LA, Zou Y (2006) Wnt-Ryk signaling mediates medial-lateral retinotectal topographic mapping. Nature 439:31-37.

Serrano A, Robitaille R, Lacaille JC (2008) Differential NMDA-dependent activation of glial cells in mouse hippocampus. Glia 56:1648-1663.

Sin WC, Haas K, Ruthazer ES, Cline HT (2002) Dendrite growth increased by visual activity requires NMDA receptor and Rho GTPases. Nature 419:475-480.

Stellwagen D, Malenka RC (2006) Synaptic scaling mediated by glial TNFalpha. Nature 440:1054-1059.

Theodosis DT, Poulain DA, Oliet SH (2008) Activity-dependent structural and functional plasticity of astrocyte-neuron interactions. Physiol Rev 88:983-1008.

Todd KJ, Serrano A, Lacaille JC, Robitaille R (2006) Glial cells in synaptic plasticity. J Physiol (Paris) 99:75-83.
Verkhratsky A, Kettenmann H (1996) Calcium signalling in glial cells. Trends Neurosci 19:346-352.

Verkhratsky A, Kirchhoff F (2007) NMDA Receptors in glia. Neuroscientist 13:28-37.

Volterra A, Meldolesi J (2005) Astrocytes, from brain glue to communication elements: the revolution continues. Nat Rev Neurosci 6:626640.

Wang YF, Hatton GI (2009) Astrocytic plasticity and patterned oxytocin neuronal activity: dynamic interactions. J Neurosci 29:1743-1754.

Weissman T, Riquelme PA, Ivic L, Flint AC, Kriegstein AR (2004) Calcium waves propagate through radial glial cells and modulate proliferation in the developing neocortex. Neuron 43:647-661.

Willmott NJ, Wong K, Strong AJ (2000) A fundamental role for the nitric oxide-G-kinase signaling pathway in mediating intercellular $\mathrm{Ca}^{2+}$ waves in glia. J Neurosci 20:1767-1779.

Yang Y, Ge W, Chen Y, Zhang Z, Shen W, Wu C, Poo M, Duan S (2003) Contribution of astrocytes to hippocampal long-term potentiation through release of D-serine. Proc Natl Acad Sci U S A 100:1519415199.

Zhuo M, Laitinen JT, Li XC, Hawkins RD (1999) On the respective roles of nitric oxide and carbon monoxide in long-term potentiation in the hippocampus. Learn Mem 6:63-76. 